\title{
Preferential Admission Policy for Ethnic Minorities in Yunnan, China
}

\author{
Dongyuan Deng \\ Faculty of Foreign Languages and Cultures \\ Kunming University of Science and Technology \\ Kunming, Yunnan Province, China 650500 \\ dengdongyuan@126.com
}

\author{
Yunqian Gao \\ Faculty of Foreign Languages and Cultures \\ Kunming University of Science and Technology \\ Kunming, Yunnan Province, China 650500 \\ gyq123301@126.com
}

\author{
Yu Yang \\ Faculty of Foreign Languages and Cultures \\ Kunming University of Science and Technology \\ Kunming, Yunnan Province, China 650500 \\ Yangyu589@126.com
}

\begin{abstract}
The paper depicted the Preferential Admission Policies (PAPs) in Yunnan, China as a theme in this research project with a purpose of better understanding on Yunnan ethnic minority EFL university students' perceptions of PAPs after so many years of implementation in certain social and political background of China. A qualitative research method was adopted for an investigation through interviews and documentations in Yunnan Province. Four groups of populations were taken as samples in this study. The results of the investigation revealed five facets of PAPs including both positive and negative effects on ethnic minorities. These findings have led to the conclusion that PAPs are still in need at present stage to help ethnic minority students achieve education equality in Yunnan, China.
\end{abstract}

Keywords_PAPs; ethnic minority; NCEE; Yunnan

\section{INTRODUCTION}

According to corresponding references, education for ethnic minorities was paid considerable attention by the Chinese government since 1949:

"The development of education for ethnic minorities is of paramount importance to the improvement of the quality of the minority population and the promotion of economic and cultural development in ethnic minority areas" [1].

Since 1978 China has undertaken a series of economic reforms designed to improve its socialist economy. Later, in the 1980s preferential policies were introduced into China as a means of closing the ethnic gaps in living standards and education. According to corresponding references, education for ethnic minorities was paid considerable attention by the People's Republic of China (PRC) government since 1949 and

This work was supported by Yunnan Provincial Foundation for Philosophy and Social Sciences on Education Program [Grant No. AC16013; 2015Y087] ; and also supported by a key research project of Humanities and Social Sciences from Kunming University of Science and Technology [Grant No. skpyzd201704], People’s Republic of China. it became an explicit policy in the middle of 1980s.

Currently, China's economy is one of the world's fastest growing market economies. However, there is still a large gap between the poor and the rich. It is estimated by UNESCO, the economic disparity in China between the poorest and most prosperous regions is greater than that between the world's richest and poorest countries. As is well known to all, most of China's minority population lives in the poorer areas such as mountainous highlands, nomadic pastoral localities, and in border areas. China's official state policy puts emphasis on the overall continued stability and improvement of economic conditions in the entire nation, taking the improvement of minority conditions as a fundamental premise [2].

Briefly speaking, three principles are the basis for the preferential policies: equality for ethnic minorities, territorial autonomy, and equality for all languages and cultures. Preferential Policies are supposed to safeguard its territorial integrity and great unity of all ethnic groups, serve its ideological goals, and accommodate the minority communities' linguistic and cultural diversities in order to achieve "the great unity of all ethnic groups" and "social solidarity and stability". The policies giving preferential treatment to ethnic minorities in China were modeled after those by the Soviet Union [3]. In the 1990s, Chinese scholars studied the dissolution of the USSR, and it turned out to be that economic inequalities and power imbalances were the main cause of the collapse.

With time passing by preferential policies (PPs) gradually cover several aspects, for example, minorities receive proportional representation in local government; no taxes in minority regions are required to be sent to the central government; higher-level jurisdictions ask lower-level minority areas to put forth "extensive efforts to support the country's construction by providing more natural resources" and in exchange gives them infrastructural subsidies such as personnel training, budgetary subventions, and 
disproportionate public works investments [3]. The Chinese government encourages business to hire minorities and offers no-interest loans to businesses operated by minorities. As far as education is concerned, the policies mainly include: The creation of special schools and classes for minority students; an emphasis on training teachers of minority youth; an increase in financial support for minority education; Additional scores awarded to minority candidates on national examinations [4].

\section{Preferential Admission Policy (PAPs) in EDUCATION}

With the implication of the PPs, Preferential Admission Policies (PAPs) for ethnic minorities also came into being. Compared with the PPs which are available only to minorities who remain in autonomous areas, PAPs are extended without regard to residence in the minority areas. A theoretical introduction on PAPs based on a review of the history and current circumstances has been formulated in education, which is with a purpose of lowering the "threshold", i.e. minimum requirements for the National College Entrance Examination (NCEE), for certain ethnic learners even including Han students who live in minority inhabited areas to enter university. This policy therefore can be adopted by a wide range of the minority population (like one-fourth of the total minority population) that is mostly integrated with the Han [5].

In education, PAPs were initiated in the summer of 1950 after the establishment of the PRC when the Ministry of Education (MOE) issued the "Regulations on Admission into Colleges \& Universities", which stated that "students of minority nationalities, industrial workers, soldiers and cadres who have three years of work experience, students whose parents are overseas Chinese, may enter colleges and universities with comparatively lower admission scores" [6].

Ever since the 1950s, the PRC government has been putting emphasis on some special groups of people's development in education through preferential policies in order to create equal opportunities for education, and above all, to maintain stability of the state. The affirmative program of PAPs is aimed to help more ethnic minority students overcome obstacles in achieving academic achievement, which allows a large numbers of minority students to have access to more education opportunities and be more successful in their academic performance from the elementary through the tertiary levels.

If we take a historical retrospection, the PAPs, which mean "lowering admission scores" policy, reflected the low standards of ethnic minority students at average in that period, which increasingly raised difficulties for them to compete with Han counterparts. In 1977, the very first years after the national university entrance examination was restored, responding to the call of developing science and education of China by Deng Xiaoping, the enrolment rate of ethnic minority students in universities witnessed a decrease: few ethnic minority students could pass the NCEE because of poor educational conditions. Afterwards, policies were further standardized and legitimated through the "Provisional Regulations on College/University Admission”, which the
MOE endorsed in 1987. Meanwhile, some universities set quotas for ethnic minority (non-Han) student intake [7]. Furthermore, minority students enrolled in ethnic minorityoriented specialties (e.g. language and literature programs) are provided with scholarships, and some of them pay no tuition, and are granted a monthly stipend.

\section{EThNicity Diversity IN YunNAN Province}

Yunnan is the most southwest province of the People's Republic of China (PRC), covering an area exceeding 394,000 square kilometers and a population of 38.85 million. Externally, it borders Vietnam, Laos and Burma; internally, it is neighbor to Guizhou, Guangxi, Chongqing, Sichuan and Tibet. Yunnan's minority population is considerably larger than the entire population of many small countries, such as Senegal, Cambodia, Cuba and Portugal, to name just a few, which has approximately taken up 33.6\% of Yunnan's population. Compared with an $8 \%$ ethnic minority population for China as a whole, this proportion is quite high [8]. Now it has 8 autonomous prefectures and 29 autonomous counties, which cover $70.2 \%$ of the provincial territory, inhabited by $48.08 \%$ of the provincial population [9]. What is unique for Yunnan province to the world is that there are twenty-five ethnic minority groups in Yunnan. The largest populous ethnicities in Yunnan are Yi, Hani, Bai, Dai, Zhuang, Miao ethnicity, whose population is over one million (China Statistical Yearbook, 2016).

Through long historical development, ethnic minorities have formed different folk customs as a kind of interesting social phenomenon. These ethnic minorities live together over vast areas in the region while some live in ethnic compact communities in small areas. The residences of the ethnic minorities are various and with different characteristics; their languages are distinctive. With increasing population mobility in China today, some minority ethnic groups and the Han majority no longer remain in one geographic region of the country. As Hansen stated, "there is a great tendency to regard all of them as one relatively homogenous group of people in need of more or less uniform special considerations within education" [10]. Although Yunnan is unique in diverse minority languages and cultures, the education of ethnic minority learners are less attended and explored.

\section{InVESTigations AND Findings of PAPs In YunNAN PROVINCE}

Historically speaking, the PAPs for ethnic minorities were figured most prominently in Yunnan's implementation of central laws and policies. In 1950 the Yunnan Provincial CCP committee and government divided minority communities into two zones, i.e. a border zone and an inland zone. In 1952 a buffer zone was added between the two for the purpose of policy implementation (Yunnan, 1994). In the allocation of the experimental status, consequently, minority communities located in the border zone were given priority over those located in the buffer and inland zones. For example, the Hani and Naxi communities are within the border zones, while the Bai and Yi are located in the buffer and inland zones. 
In order to know more clearly on the PAPs, relevant documents and files were looked up. Based on relevant documents, the 1980 Regulations made it clear that "minimum admission scores can be lowered for those minority candidates from compact ethnic minority communities dwelling in mountainous highlands, nomadic pastoral localities, and in border areas" for the first time. Ever since, a great number of ethnic minority students became beneficiaries of the PAPs.

The 1980 Regulations laid down differentiated preferential policies for ethnic minority students from non-compact ethnic minority communities and compact ethnic minority communities. In addition, the 1980 Regulations required certain key universities/colleges to establish special classes for ethnic minority students, which are also called Preparatory Courses (Yuke, Preparatory Classes). Minimum admission scores were greatly reduced to ensure ethnic minority students to enter these special classes. As a result, the regulations had the effect of greatly increasing higher education opportunities for ethnic minorities.

Previous studies of preferential policies tend to put the emphasis either on providing us justifications from policymaking perspectives or on summarizing lessons learned. Indepth analysis into perceptions of these policies from the perspective of ethnic university students, teachers, administrators and even government officers remains rare. What are Yunnan ethnic minority EFL university students' perceptions of PAPs? How should we evaluate these polices? In order to understand participants' perceptions of PAPs, some questions were designed for the interviewees: (1) Do you think PAPs supportive for ethnic minority students in higher education or not, why? (2) What advantages or disadvantages of PAPs in your opinion? (3) Do you think ethnic minority students are really in need of PAPs? The study was in an attempt to find some answers to these questions from different perspectives of various informants through interviews and documentary method. The interviews were conducted through four layers of informants: (1) the student informants who were from four different universities: Kunming University of Science and Technology (KUST), Yunnan Minzu University (YMU), Dali University (DU), and Chuxiong Normal University (CNU). They were with different ethnic backgrounds and originally either from border zones or from buffer and inland zones, mainly undergraduates, and a small number of MA students; (2) the teacher informants who were EFL teachers working with non-English major students of different levels; (3) the administrator informants, two of them were the heads of Faculty of Foreign Languages and Cultures respectively working at DU and CNU, and the other one was in charge of curriculum development and policy making at YUM; (4) officers who worked in Yunnan Provincial Education Department (YPED) and Kunming Education Bureau (KEB).

As Yunnan's minority ethnic university students were from different regions and with various social, economic, and geographic backgrounds, in this study, to single out the most representative informants, purposeful sampling was adopted by choosing some informants who were representative in age, gender, ethnicity and language diversity. And above all, students from small ethnic groups living in compact ethnic communities and students from large ethnic groups living in buffer and inland zones were interviewed. The main findings of the study are to be illustrated as follows from five facets.

\section{A. Socioeconomic and Geographical Constraints}

In recent years, the rapid socioeconomic development of China in the past decades provides ethnic minorities with unprecedented historical opportunities in overall development. For example, since 1999, the central Chinese government as well as the local have made a series of policies to promote the socioeconomic development in China's western regions, such as the policy on "China's western development” (2000, 2001, 2004, 2010); Schema of building Yunnan into a "great ethnic cultural province” (2000), "building Yunnan into a 'gateway to the southwest” (2011), Regulations for Ethnic Minority Education in Yunnan (2011) etc. [11], to name just a few. But due to historical reasons, the socioeconomic conditions of compact minority regions usually fall behind with noncompact ethnic regions, so as to border zones to buffer and inland zones. A sophomore boy student of YMU from the Lisu Autonomous Prefecture of Nu Chiang, shared his story:

My family lives in mountain areas of Nu Chiang. We've been living there for generations. When I was a child, my little fellows and I often walked for a long distance to school because there was no school in our village. When I entered into secondary school, that one was even further and I had to board there and came back home once a week. (Lisu S-1, YMU) Another girl from DU said,

...My parents are peasants. They are almost illiterate, even not finished their primary school at their times, while they insisted on supporting for my schooling and education just because they wished me be able to "walk out of the mountain". I think we should thank the PAPs. (Bai S-1, DU)

Ethnic students' locations or origins have gradually become a key element in PAPs implementation. Minority student applicants from compact border zones, due to the poor economic condition, normally can take PAPs bonus points of maximum 20, but minority student applicants from noncompact ethnic minority areas especially buffer and inland zones are not entitled for the policy privilege of lowering that many of admission scores. For example, the Bai community is located in the buffer and inland zones, and the Yi covers the largest areas in Yunnan, while the Hani and Naxi communities are within the border zone, if not taking those small scattering places into consideration.

On the other hand, the poor natural geographical environment to a large extent restrains the local economy development of ethnic regions. Due to some historical reason, most ethnic minorities live in mountainous highlands, nomadic pastoral localities, and in border areas, where economic development is severely restricted by physical geography conditions. One of the teacher interviewees, Ms Li 
Xiao (she herself is Yi nationality), expressed her standpoint as follows:
I think it is mainly the location (region) that restraints the development of ethnicities, not ethnicities themselves. If you live in a big city or nearby, you may have access to better educational resources, good quality of teachers, and good language environment. This is something related to social and economic development. (Yi T-1, CNU)

As a matter of fact, remoteness often brings backwardness in economy and social culture, which reversely hinders the development of a regional education for ethnic minorities.

Though the PRC government has been making efforts in promoting economic development in the ethnic autonomous regions, which normally are in form of state-led industrialization projects, state subsidy to animal husbandry and agricultural activities etc., there is still a big gap between different regions. As a result, the whole education conditions are distinct especially from the city to the countryside, let alone rural and mountainous areas.

\section{B. Positive Affirmation of PAPs}

In the white paper on Ethnic Minorities Policy in China (1999), the PRC government stated "Promoting the Common Development of All Ethnic Groups" as one of the five major aims in country's ethnic minority policy. Therefore, in the practice of ethnic minority policy, socioeconomic development is of great importance in the state's agenda. As for bonus points on the NCEE (Gaokao), Article 8 of Higher Education Law of the PRC stipulates that:

\section{In light of the characteristics and needs of the ethnic groups, the state assists and supports the development of higher education in regions inhabited by ethnic peoples for the purpose of cultivating ethnic talents and training senior specialists among them (National People's Congress 2005).}

The PAPs of NCEE in Yunnan province regulate that 19 ethnicities in buffer and inland zones can get 10 bonus points including the Hani, Dai, Miao, Lisu, La, Wa, Jingpo, Yao, Bulang, Nu, Achang, Pumi, Deang, Dulong, Zang, Mongol, Jinuo, Shui, Buyi. But if ethnic candidates are from compact ethnic minority communities in mountainous highlands, nomadic pastoral areas, and border areas, they may apply for 20 bonus points. A Hani student from Yuanyang,a compact ethnic minority county of Hani people, made a positive comment on the PAPs:

We all know Yuanyang Hani Terrace now, but how and why Hani people had to cultivate paddy on the slope of mountains? We have only a few flatlands and people have to be creative. Surely we need some support from the government, otherwise, how can we compete with others who live and get educated in those big cities? We have totally different platforms.

(Hani S-4, KUST)

The Jingpo ethnicity is another branch of ethnic minority living in compact and border zone in Dehong Autonomous Prefecture. A Jingpo girl, majored in Chinese Ethnic History also gave some supportive voices even to the Han in border zone:

It is quite well to add "bonus points" to students from remote areas, not only ethnic minorities, but also some "special Hans". In my county, so many children from "educated urban youth" (Zhi Qing) family were admitted to Peking and Tsinghua University. Their parents were normally better educated than the local and those students were often the tops in class. They enjoy the PAPs too. (Jingpo S-6, YMU)

During the interviews, ethnic minority university students are not unaware of a mixed ethnic environment of different ethnic groups. When the investigator asked on the preferential admission policy especially for the students from compact and border zone areas, they confirmed far more advantages than disadvantages.

\section{Supportive Voices of PAPs from Other Perspectives}

For PAPs on ethnic minority students, almost all the informants of teachers, administrators, and officials expressed their supportive attitudes. Mrs. Du, a EFL lecturer having working at YMU for six years, and Mrs. Gao, an associate professor of EFL also from YMU, and Mr. Li, a teacher in Division of Foreign Language Education at CNU, spoke highly of PAPs. One of them said,

\begin{abstract}
We are teachers from ethnic minority backgrounds ourselves and we have had the experience of going through a long journey from being poor countryside children to university lecturers. We understand very well how eager these students, together with their families, are to get higher education. (Zhuang T-1, YMU)
\end{abstract}

Furthermore, three administrators, including two involved in policy-making from YMU, DU, and CNU were interviewed individually. They were from 3 different ethnic minority backgrounds and had at least 10 years working experiences in the field of ethnic minorities' education. The two interviews with the administrators took place in their offices and the other one was held in her residence. Notes were taken while the interviews were going on. The key issue to discuss was on PAPs.

There was a common concern from three of them that the aim of higher education for ethnic minorities was to produce more professional personnel for the ethnic minority areas. One administrator from YMU said,

We must ensure that politically everybody, no matter what ethnicity she/he is, has equal rights to be 
educated. In order to achieve this goal, YMU together with other higher education institutions have to give respect to the ethnic minorities who wish to use their own languages, writing scripts and keep their ethnic identities. (Zhuang Adm-1, YMU)

Another administrator, Dr Wang, who is a typical cadre with ethnic minority background, expressed his devoted ambition toward ethnic minority education:

\begin{abstract}
Personally I strongly support the bonus-points preferential policies because I myself am a beneficiary of it. I still remember in the year I went to university, the cut-off line (the NCEE enrollment points) was 420 for science and 410 for humanities. My scores were 387. Together with the adding points, I finally was able to go to university. After that, I kept working hard, and now I'm the only one university teacher with doctor degree. The whole village is proud of me, and many relatives and villagers take me a sample as their children, and I'm very thankful. (Bai Adm-2, DU)
\end{abstract}

By conducting some interviews, the two administrators of Zhuang and Bai expressed there was the need to pay attention to the cultural study of the different ethnic minority groups. And, there was a real need to attach importance to the small minority groups and create more opportunities for their higher education. These issues were regarded as the main aspects of the present government's policies for ethnic minorities according to the administrators interviewed.

During the interviews, the two administrators of Zhuang and Bai expressed there was the need to pay attention to the cultural study of the different ethnic minority groups. And, there was a real need to attach importance to the small minority groups and create more opportunities for their higher education. These issues were regarded as the main aspects of the present government's policies for ethnic minorities according to the administrators interviewed.

Furthermore, in order to get to know more about PAPs implementation situation of Yunnan province, relevant interviews were conducted either though a face-to-face talk or via email and Wechat with two officials working at YPDE and KEB.

Zhang Liang, a Naxi official working in YPDE, stated that preferential policy was not a purely logical process, but much more still depended upon the balance struck between competing views and interests. He illustrated:

Actually Yunnan government has been doing a comparatively good job in promoting ethnic minority education. But this is a comprehensive and complex project. For example, there are 19 ethnic minority groups being able to enjoy bonus points of 10 in 2016 based on PAPs. Those who live in border zones may get at most 20 points. If the Han's children are born and grow up there, they get the same bonus points; while if students spend their senior high school in inland zones, 10 points are deducted. Some ethnicities, like Zhuang and Yi, if they live and study in inland zone, but in the countryside, they only get 10. Anyway, things vary from different ethnicities, areas, and also their parents' conditions. (Naxi Official-1, YPED)

Simultaneously, an official from KEB told me that in electing and appointing cadres by the government, the one with ethnic minority background normally had more advantages than the Han if they were neck and neck in other qualifications. But as for PAPs, there were some problems as well:

As this problem is subtle and sensitive, the government has tried the utmost to ensure a fair implementation. But of course, we have ever found a few applicants resort to deceit in order get the bonus points. But that is very risky. Of course, we've received some reports to call for cancelling the preferential admission policies (PAPs) to achieve a so-called "fair" competitive environment. Most of these voices are from the Han majority, while I don't think they really understand the conditions of those ethnic beneficiaries and the history. (Han Official-2, KEB)

\section{Limitations of PAPS}

PAPs undoubtedly have helped a lot ethnic minority students gain better chances to acquire good education at different stages, but at the same time they have actually caused some problems in equality as well. For example, Sautman (1999) points out that the Hui (Chinese Muslim) who live in some relatively prosperous places in China has benefited a lot from PAPs because the Hui's educational level is never lower and even higher than that of the Han [5]. The Hui has a traditional background in commerce and most of them are more prosperous than the Han, which gained them a reputation of "Chinese Jews". In this case, it seemed to be somewhat ironic that the Hui, one of the most prosperous ethnic groups have benefited a lot from PAPs which were originally intended to reduce the gap between the developed Han majority and other underdeveloped minority ethnic groups.

On the other hand, due to "historical factors and geographic remoteness" [12], those areas are seen as less developed areas. As for education, the ethnic minority students are confronted with more difficulties than the Han in a general sense and it's more challenging for them to meet the same standards or requirements as Han students. When in the tertiary EFL learning, things are the same.

At tertiary level, ethnic minority students are expected to have the same requirement as Han students, i.e. not only master generic skills, but also the language proficiency in Mandarin Chinese (Putonghua) as the national language, and also English. 
However, as we mentioned above, the culture, language, and socioeconomic gaps between the minority ethnic groups and majority Han usually place ethnic minority university students at a great disadvantage. When it came to the effect of the PAPs, Mrs. Zhao, a chair from CNU also expressed her worries:

I think the most important thing is that the teaching quality has to be guaranteed. And the provincial government had better offer more sponsorship to support ethnic minority areas' education construction. The bonus points do help, but only temporarily. After entering into university, if those ethnic minority students don't work hard, they will fall far behind after one year or two. ( Han, Adm-3, CNU)

Actually, the PAP offers are limited by many extra conditions as it was mentioned before, like the origins of students, not only ethnicities. Moreover, not all ethnic minorities can benefit from PAPs, actually those minority students with either too low or too high scores are excluded. That is to say, PAPs are effectively applicable only to those students whose scores are just behind within a critical range below the cut-off line of NCEE. The candidates are only selected from some distinctive ethnic groups in terms of its socioeconomic development, the size of population, and the ethnic locations.

However with PAPs bringing ethnic minority students some benefits to get access to higher education in China with lower "threshold", some embarrassment also accompany those students. In a focused group interview, several students of Yi also told me that they would not talk about the PAPs because it would make them feel a little embarrassing, a sort of feeling like they were inferior to others:

Student A: There are not many ethnic minority students in my class. Most of them are Han. Once in a while I was asked about this question, maybe I was a little oversensitive, I felt I got "a different look" from my classmates...really awkward. [em...] I don't want to be different from others [getting bonus-points]. It seemed that I gained extra advantage by unfair means. (Yi S-6, CNU)

Student B: I had sort of similar feeling on this problem though it seemed very common in my university [CNU] since most of us are beneficiaries [of preferential policies]. I remember in my senior high school, some students didn't study hard enough but they still entered university due to the policy. I'm afraid that this [preferential policies] will unconsciously make ethnic students lazy. (Yi S-7, CNU)

Student C: I know that some ethnic minority students around ever attended Preparatory Courses (Yuke) before college/university. Some of them behaved poorly in academic attainment at school. But I heard that some of their parents had Guanxi, which enabled them to rise to university as well. (Yi S-8, $\mathrm{CNU})$

\section{E. Preparatory Courses (Yuke) as a type of PAPs}

Yuke, means Preparatory Courses, refers to pre-university education program organized by minority nationality high education institutions in China especially for ethnic minority students, who are required to complete one-year preparatory courses. And on the premise of passing all, they can directly further enter into university or college to be university students. Generally speaking, Yuke (Preparatory Courses) has been playing an important role in enhancing ethnic minority education.

When talking about Yuke program, Wang Baoming, a 22year-old male student from Miao nationality, and a sophomore student majored in Economics Law shared his story. He said this was the 3rd year to attend YMU, one year for the Yuke program and two years for the undergraduate program. Wang Baoming grew up in a poor peasant family in a remote village of Luqian, which belongs to buffer zone. He told me that his father had high expectations for his children and wished them get a better education. According to Wang, he was always the top student in his class until he finished junior middle school (equivalent to a junior high school in the US). He used to walk or ride a bicycle to school which was about 10 kilometers from his home. In the year of NCEE, his father died. Under the control of bitter grief, he couldn't pass the cut-off line even with 10 bonus points. Thanks to his teacher, who was in charge of his class, he was recommended to YMU preparatory courses program by his senior high school.

\section{DisCUSSIONS AND CONCLUSION}

The latest 12th National Socioeconomic Development Plan proposes socioeconomic development in Tibet, Xinjiang, Yunnan and other ethnic minority areas and help the ethnic minorities with comparatively small populations. As for education, the government promises to promote educational equality by allocating more public educational resources to those poor and rural ethnic minority areas. The Outline of National Middle and Long-term Educational Development (2011) are implemented to attach more significance and support for ethnic minority education and improve the overall educational conditions and development for ethnic minorities in China.

In recent decades, the center government of China has come to decentralize the power to provincial authorities and entitle different provinces to the right to set up indicators and criteria of implementing preferential policies including PAPs which were formerly in the hands of central government. The PAPs in education have been implemented nationally in China. In the light of diversities and imbalance among ethnic minority groups and different regions, Yunnan province has implemented concrete and specific regulations and practices. Some points can be summarized below: 


\section{A. PAPs Are in Need}

China's PAPs aim to help all ethnicities achieve common prosperity, valuing not only equality in legal rights, but also equality in daily life. Having equal education opportunity especially for higher education should not only be a question of equal admission, but also a reflection on equal education starting points, processes and achievements. The realistic difficulties of ethnic minorities due to the history and current circumstances need to be taken into consideration dialectically. On the surface, PAPs seem to violate individual equality in college/university admission. However, the practice turns out to be a great step towards ethnic equality. If only one admission line were applicable nationwide, far less ethnic minority students from rural remote mountainous ethnic minority areas especially in the western part of China would ever have access to high education, as there is still a wide education gap between those of ethnic minorities and the majority Han Chinese.

\section{B. Ethnicity Doesn't Count All the Way}

Though there are many supportive policies to enhance Yunnan socioeconomic reform, the realistic backward living and educational condition still largely exists. Educational gap mainly comes from regional differences. In Yunnan Province, minority students from mountainous highlands, border areas, nomadic pastoral areas and other compact ethnic minority communities can have bonus points added onto their NCEE scores, which is a priority in university admission over most Han Chinese students under identical terms and conditions. Simultaneously, students from poverty-stricken ethnic minority autonomous places, no matter they are the Han, Hui or other ethnicities, are granted 10 or more points than other students. It is also worth mentioning that it is the regions rather than ethnicities really count in the PAPs of lowering admission scores to universities. That is to say, similar PAPs are extended to even Han Chinese students who have lived a long time in ethnic minority areas in order to guarantee equal access to education rights, opportunities and resources.

\section{Different Voices in PAPs Exist}

Based on data analysis, most ethnic university students were in favor of "bonus points" or "lowering admission scores" PAPs but insisted that they should be implemented in a controlled way. Also, PAPs aroused some worries of students and teachers as they thought the help was only temporary, and it was the improvement of fundamental education conditions and ethnic minority students' self-esteem that could really facilitate the education level of compact border zones of minority communities. In addition, PAPs brought some bias and negative feeling to ethnic minority beneficiaries as well.

\section{Yuke Remains Controversial}

Specific ethnic minority classes are required to take only for ethnic minority students to prepare them into higher education. But relevant administration work needs to be supervised in case some people take advantage of it. Otherwise, the fairness of Yuke will be spoiled. It is unfortunately true that a small number of dishonest Han students have ever created fraudulent identity files to get the bonus points. Anyway, the prospect of ethnic minority students mostly depends on their own hard work beside the platform of PAPs.

\section{SUMMARY}

At present, PAPs are of significance to enhance education equality for ethnic minority students in China. The study indicates that the Preferential Admission Policies (PAPs) function as an effective guarantee of comparatively equal access to education opportunities education rights, and resources for those ethnic minority students whose scholastic attainment is not good enough for NCEE owing to external constraints from society, family and school. The study also shows that for ethnic minority students who manage to gain access to universities, affirmative action like PAPs plays its intended role of enlarging and diversifying the minority groups.

\section{REFERENCES}

[1] National Minorities Policy and Its Practice in China, 2004 (12), p.18. Retrieved on October 11, 2006, from http://www.chinaun.ch/eng/bjzl/tl76942.htm.

[2] Wang, Y., \& Phillion, J. Minority language policy and practice in china: the need for multicultural education. International Journal of Multicultural Education (1), 2009, pp.1-14.

[3] Barry Sautman. Preferential policies for ethnic minorities in China: The case of Xinjiang. Nationalis $m$ \& Ethnic Politics, 1998, 4(1-2), pp.86-118.

[4] Lee, E., \& Norton, B. The English language, multilingualis m, and the politics of location. International Journal of Bilingual Education and Bilingualism, 12(3), 2009, pp. 277-290.

[5] Sautman, B. V. Expanding Access to Higher Education for China's National Minorities: Policies of Preferential Admission. In China's National Minority Education Culture, Schooling, and Development, 1999, p.175.

[6] Ministry of Education (2002). Putong gaodeng xuexiao zhaosheng gongguo guiding. [Regulations on higher education institutions admission]. Available online at: http://www.eol.cn/article/20020227/3038948.shtml (accessed 2 March 2006).

[7] Hasmath, R. What explains the rise of ethnic minority tensions in china? Social Science Electronic Publishing, 2013, p.50.

[8] Zhang, J. Collaborative instructors and mixed learners: An English for specific purposes teaching model in China. Canadian Social Science, 7(5), 2011,pp. 144-150.

[9] Wang, G. Ethnic multilingual education in China: A critical observation. Working Papers in Educational Linguistics (WPEL), 30(2), 2015, p.3.

[10] Hansen, M. H. Lessons in being Chinese: Minority education and ethnic identity in Southwest China. University of Washington Press, 2011, p.167.

[11] Fan, K. Representation of ethnic minorities in socialist china. Ethnic \& Racial Studies (12), 2016, pp.1-17.

[12] Hansen, M. H. Lessons in being Chinese: minority education and ethnic identity in Southwest China. Hong Kong University Press, 1999, p.158. 